\title{
Saúde coletiva, resíduos sólidos urbanos e os catadores de lixo
}

\author{
Urban solid residues, garbage collectors and public health
}

M ônica M aria Siqueira ${ }^{1}$

M aria Silvia de $M$ oraes $^{1}$

\footnotetext{
${ }^{1}$ Departamento de Epidemiologia eSaúde Coletiva, Faculdadede M edicina deSão Josédo Rio Preto. Av. Brigadeiro Faria Lima 5416, Jardim Panorama. 15090-000 São José do Rio Preto SP. msiqueiralopes04@ yahoo.com.br
}

Abstract The article approaches the issues of environmental production and the generation of urban solid residues, in particular the environment and health concept while social representation. From a bibliographical revision it argues the incorporation of the themes of health and environment in the practical field of knowledge and of interconnection with the Public Health. In this context it associates the question of the social exclusion generated by the form of production and consumption of the after-modern society, introducing the garbage collectors as a vulnerable population group.

Key words Urban residues, Public health, Garbage collectors, Environment
Resumo 0 artigo aborda a problemática ambiental da produção e da geração de resíduos sólidos urbanos, destacando o concei to de saúde e de ambiente enquanto representação social. A partir de uma revisão bibliográfica, discute a incorporação da temática saúde e ambiente no campo de conhecimento e práticas de interconexão com a saúde coletiva. Associa nesse contexto a questão da exclusão social gerada pela forma de produção e de consumo da sociedade pós-moderna, introduzindo os catadores de lixo, grupo populacional vulnerável.

Palavras-chave Resíduos urbanos, Saúde coletiva, Catadores de lixo, Ambientes 
Introdução

São grandes os desafios e as inquietações da sociedade moderna frente aos diagnósticos ambientais e seus efeitos desencadeantes na saúde das populações.

0 presente artigo delineia-se a partir do conceito deambienteconstruído na teoria social pósmoderna, relacionando os sistemas de produção da sociedade com a demarcação dos índices de consumo adotados pela população e seus efeitos na saúde do ambiente e do próprio indivíduo. Assinala-se, nessa discussão, como uma das consequências desse processo, o surgimento da população de catadores de lixo, como um fenôme no na escala da exclusão social instalado na sociedade, provocado pela forma de consumo instituída e pela geração de resíduos sólidos urbanos.

\section{Saúdee ambiente: a necessária interface}

Desde a antiguidade, relatam-se efeitos na saúde provocados pelas condições ambientais. 0 rápido processo de industrialização e de urbanização nos meados do século XVIII eXIX desencadeou consequências na saúde da população advindas da problemática ambiental instalada no período ${ }^{1}$.

As práticas sanitárias aí iniciadas visavam à redução e eliminação das doenças provocadas pelo ambiente, surgindo o termo higiene, utilizado como estratégia de saúde em que a vigilância e o controle dos espaços urbanos e dos grupos populacionais passaram a ser monitorados de maneira sistemática².

É a partir da segunda metade do século XX que a inter-relação da saúde com 0 ambiente se insere nas preocupações da saúde pública, cuja definição dada pela OM S é: "saúde ambiental é o campo deatuação da saúde pública quese ocupa das formas de vida, das substâncias e das condições em torno do ser humano, que podem exercer alguma influência sobre a sua saúde e o seu bem-estar".

Segundo Augusto 4 , é com essa definição que o conceito de saúde mostra-se claramente como resultante das condições de vida e do ambiente. Ao mesmo tempo em que degradam o homem, sua qualidade de vida e seu estado de saúde, os padrões de desenvolvimento adotados vêm favorecendo a degradação ambiental por meio da exploração predatória de recursos naturais e poluição, às quais, por sua vez, têm gerado grandes impactos nas con dições de saúde e qualidade de vida da população.
A construção do conceito de saúde passa assim a não ser abstrata, definindo-se no contexto histórico da sociedade e em seu processo de desenvolvimento, englobando as condições de alimentação, habitação, educação, renda, ambiente, trabalho, emprego, lazer, liberdade, acesso e posse da terra e acesso a serviços de saúde.

A partir dessa análise, a criação de ambientes adequados à saúde provoca o reconhecimento da complexidade das sociedades e das relações deinterdependência entre suas diferentes esferas.

Assim, a proteção e a conservação dos recursos naturais, o acompanhamento sistemático do impacto que as modificações no ambiente lançam sobre a saúde, bem como a aquisição de ambientes que facilitem e favoreçam a saúde, como o trabalho, o lazer, o lar, a escola e a própria cidade, passam a compor centralmente a agenda da saúde, estando associados à qualidade de vida das populações 5 .

Segundo M inayo ${ }^{6}$, a abrangência do conceito de qualidade de vida e seus muitos significados podem ajuizar variedade de conhecimentos, experiências e valores de sujeitos e suas coletividades inseridas em variadas épocas, espaços e histórias diferentes, sendo, portanto, uma construção social com a marca da relatividade cultural.

Em suma, o modo como os homens vivem, adoecem e morrem, além das percepções culturais e de características individuais (imunogené ticas), é fortemente condicionado pelo modo como a sociedade produz e distribui suas riquezas ao longo de sua história.

\section{Ambiente e o processo de construção}

A definição deambiente deveser entendida a partir do contexto sócio-histórico em que são formulados os seus significados ou por meio das relações estabelecidas pelos diversos grupos culturais que o compõem.

Segundo Left ${ }^{7}$, o entendimento de ambiente deve se pautar na racionalidade ambiental, na transdisciplinaridade, pensando não como um sinônimo de natureza, e sim como base de interações entreo meio físico-biológico com as sociedades e a cultura produzida por seus membros.

Para Carvalho ${ }^{8}$, desde que os conceitos de natureza e ambiente abandonaram os limites da ciência ecológica e designaram uma agenda de lutas sociais, passaram a ser vistos não apenas como mais uma questão a ser equacionada pela lógica científica, mas, sobretudo, como um valor crítico do modo de vida dominante, em torno da 
qual tem se organizado um importante debate acerca de novos valores éticos, políticos e existenciais que deveriam reorientar a vida individual ecoletiva.

Giddens ${ }^{9}$ discute quea determinação de ambientes criados não se encontra alheia à vida social humana, mas, sim penetrada e reordenada, confundindo o que é "natural" com o que é "social".

Diagnóstico global:

resíduos sólidosurbanos

Permeando essas reflexões, tem-se que, de todos os problemas enfrentados pelo sistema mundial, a degradação ambiental é o fenômeno mais globalizado e que poderá transformar-se em um conflito mundial.

Os problemas ambientais acumulam-se, 0 aquecimento global do planeta éfato eas já confirmadas mudanças climáticas registradas; a devastação das florestas, o buraco na camada de ozônio, o extermínio da biodiversidade, ainda pouco conhecida, a deterioração da qual idade do ar nas grandes cidades, o comprometimento dos fluxos de água, tanto em qualidade, quanto em qualidade, a fome e as doenças precoces ${ }^{10}$.

0 quetodas essas catástrofes têm em comum? A resposta é uma só: são decorrências, em grande parte, do atual estágio de desenvolvimento global, dos padrões de produção e de consumo.

A Agenda 21 Global, documento elaborado na Rio Eco 92, durantea realização da Conferência das Nações Unidas sobre Meio Ambiente e Desenvolvimento, no seu capítulo 4, expressa em tom de preocupação que as principais causas da deterioração ininterrupta do meio ambiente mundial são os padrões insustentáveis de consumo e produção, especialmente nos países industrializados, os quais provocam o agravamento da pobreza e dos desequilíbrios ${ }^{11}$.

Com o processo de industrialização, com a crescente concentração populacional urbana e o incentivo ao consumo como características básicas da sociedade moderna, os problemas sociais, ambientais e de saúde pública se agravam.

Para Castell $\mathrm{s}^{12}$, o sistema urbano instituído é uma expressão do sistema total do qual eleéparte: o modo de produção capitalista, qual seja, a re produção da força de trabalho através da organização do processo de consumo.

Uma diversidade detendências teóricas aponta que o maior responsável pelo quadro ambiental atual é a sociedade industrial. Gidden $\mathrm{s}^{9}$ argumenta queo industrialismo éo componentecen- tral da degradação ambiental na modernidade, tanto no capitalismo como no socialismo real, pois essa é a tônica do desenvolvimento.

Waldman ${ }^{13}$ e Caval canti ${ }^{14}$ sistematizam as causas estruturais da degradação ambiental desencadeada pelo capital ismo, argumentando que a expansão e a manutenção da demanda de produção são desencadeadas pelo consumo elevado, na média per capita, gerando uma enorme pressão na natureza. Tal, aliado ao livre mercado eà propriedade privada, incentiva a aquisição de cultura de exploração dos recursos naturais e humanos, instituindo a mercantilização da vida. Ainda, segundo o autor, a cultura de consumo se desenvolvenuma movimentação de mercado que visa à geração de lucros crescentes, causan do um aquecimento da economia que necessita constantemente de mais produção e mais consumo. E essa explosão do consumo, que aparece como modo ativo de relação das pessoas com os objetos, com a coletividadee com o mundo, constitui a base do nosso sistema cultural.

Segundo Pádua ${ }^{15}, 20 \%$ da humanidade são responsáveis por cerca de $80 \%$ do consumo anual de energia e recursos do planeta, sendo também responsáveis pela produção de $80 \%$ da poluição. Seus estudos demonstram que o planeta está dividido em três grandes blocos no que se refere ao consumo dos recursos do planeta:

- No Bloco I, encontra-se 1/5 da humanidade, aproximadamente 1,2 bilhão de pessoas, representadas pelos países da OECD (Organização para a Cooperação e D esenvolvimento Econômico). Considerados países de alto consumo, são responsáveis por $82,7 \%$ do PIB mundial, $81,2 \%$ do comércio mundial e $50 \%$ da produção degrãos, contrapondo com um consumo de $60 \%$ dosfertilizantes artificiais, $92 \%$ dos carros privados, $75 \%$ da energia, $80 \%$ do ferro e aço, $81 \%$ do papel, $85 \%$ dos produtos químicos e $86 \%$ do cobre e do alumínio;

- No Bloco II, concentram-se $3 / 5$ da humanidade, representando 3,6 bilhões de pessoas de renda média, tendo como responsabilidade a geração de $15,9 \%$ do PIB e $17,8 \%$ do comércio mundial. Produzem cerca de 30 a $40 \%$ dos alimentos primários e são responsáveis por $10 \mathrm{a}$ $15 \%$ do consumo energético e da produção industrial do planeta;

- No Bloco III, a formação ocorre com 1/5 mais pobre da humanidade, 0 que representa 1,2 bilhão de pessoas, sendo responsáveis por 1,4 do PIB mundial e $1 \%$ do comércio mundial.

Novaes ${ }^{16}$ discute que o consumismo desenfreado é a maior ameaça à humanidade. 0 esgo- 
tamento dos recursos naturais abala a qualidade de vida de ricos e pobres. 0 autor analisa dados divulgados pelo Wordwatch Institute, em seu re latório anual do Estado do Mundo de 2004, citando que a obesidade já um dos maiores problemas de saúde do mundo, atingindo cerca de $65 \%$ da população adulta dos Estados Unidos e que, no mundo, apenas 1,7 bilhão dos atuais 6,3 bilhões de pessoas têm capacidade de consumir além das necessidades básicas. Ainda, o crescimento do consumo mundial passou de US\$ 4,8 trilhões em 1960 para US\$ 20 trilhões em 2004, sendo que $60 \%$ encontram-se concentrado nos Estados Unidos, no Canadá e na Europa, onde vivem menos de $12 \%$ da população mundial.

Os efeitos deuma postura exploradora econsumista sobre o ambiente podem ser desastrosos na medida em que o homem desafia os limites externos, modificando a sua relação com o ambiente e pautando-se na tecnologia como instrumento primordial na busca de soluções para os problemas de escassez. Além disso, quando os estímulos para o consumo e as necessidades não são originados dentro de cada indivíduo, mas de fora, é normal que se desconheçam os limites das ações, ou que haja uma não responsabilização dos agentes com relação aos seus atos. Quanto mais for produzido, mais a pessoa que deseja manter o seu prestígio precisa adquirir.

Segundo Portilho ${ }^{17}$, quanto mais um homem se afasta das necessidades físicas, tanto mais re ceptivo será à persuasão sobre aquilo que consome. Talvez esta seja a mais importante consequência econômica da abundância crescente, presente nas classes sociais mais abastadas.

Santos ${ }^{18}$ alerta afirmando que a conversão do progresso em acumulação capitalista modificou a natureza em mera categoria de produção e que os limites desta transformação levaram riscos e perversidades deflagrados em uma catástrofe ecológica vivenciada pela sociedade atual.

Para configurar esse quadro, os modos de produção e consumo adotados pela sociedade desembocam, não só na exclusão social, mas nos impactos ambientais ocasionados por essa geração de resíduos provocados pela acumulação de bens.

Segundo Calderoni ${ }^{19}$, a completa solução da questão do gerenciamento dos resíduos domésticos envolve primeiramente uma profunda retomada do conceito de necessidade da sociedade, para posteriormente examinar seu correto recolhimento, transporte, disposição, tratamento ou reciclagem. 0 não tratamento do lixo, além depromover o desperdício dematerial reciclável, como metais, vidro, pano epapel, tem como contrapartida a criação de depósitos inadequados.

Embasada nesta perspectiva, essa investigação trabalha com a premissa de que problemas ambientais são problemas de saúde, pois afetam os seres humanos e as sociedades em todas as suas dimensões, ficando evidentes suas consequências no espaço construído. Quando, uma de suas tantas imagens, a população de catadores de lixo, sefaz presentena dinâmica urbana das cidades, evidenciando que o "simples" ato de consumir produtos provoca, interfere, dissemina fenômenos sociais pautados na exclusão e que afeta a saúde ambiental e coletiva do planeta, é hora de exigir mudanças nas políticas públicas vigentes e readequar os atuais modos de vida em sociedade.

Com esse embasamento, é importante efetivar a relação entre esse consumo apontado e a produção de resíduos. Tendo como base de cálculo a população do planeta, atualmente estimada em 6 bilhões de habitantes, com uma geração aproximada de cerca de 30 milhões de toneladas de resíduos por ano, se demonstra a insustentabilidadedos padrões mundiais de produção, consumo e renda al iada à qualidade de vida e a saúde coletiva.

\section{Resíduos sólidos urbanos (RSU) e sua relação com a saúde col etiva}

Os problemas relacionados aos resíduos sólidos têm se avolumado nas sociedades contemporâneas, implicando a deterioração da qualidade de vida nos grandes centros urbanos.

A degradação do meio ambientenatural não pode ser desvinculada de um contexto queinclui comprometimentos da saúde física, transtornos psicoloógi cos epsiquiátricos, edesintegração social. Assim, patologias como doenças infecciosas, degenerativas, cardiovasculares, crises de ansiedade e depressão, síndrome do pânico, dependência química e exacerbação da violência, dentre outras, são os componentes constitucionais de um mesmo fenômeno. Precisamos, pois, concordar com Capra ${ }^{20}$, que o esgotamento dos recursos naturais não ocorre isoladamente, visto que o homem é parte integrante da natureza e, portanto, sofre com toda intervenção indevida sobre ela.

Os resíduos sólidos urbanos gerados pela sociedade em suas diversas atividades resultam em riscos à saúde pública, provocam degradação ambiental, além dos aspectos sociais, econômicos e administrativos envolvidos na questão. 
Em relação à saúde pública, os resíduos sólidos urbanos ocupam papel estratégico na estrutura epidemiológica de uma comunidade. Como componente indireto, destaca-se na linha de transmissão de doenças provocadas pela ação dos vetores, que encontram no habitat do lixo condições adequadas para a sua proliferação. $\mathrm{Na}$ interface com as questões ambientais, os resíduos contaminam ar, águas superficiais e subterrâneas e, consequentemente, 0 solo ${ }^{21}$.

0 lixo coletado diariamente na área urbana das cidades é transportado para as áreas de destino final, onde, na maioria das vezes, é lançado indiscriminadamentea céu aberto, sem qualquer forma de tratamento.

A incorreta disposição final do lixo urbano, além de provocar poluição do solo, colabora para a poluição das águas e do ar. A poluição das águas acontece por meio de fenômenos naturais como a lixiviação, percolação, arrastamento, solução, etc. $\mathrm{Na}$ poluição do ar, constatam-se efluentes gasosos e particulados emitidos para a atmosfera, provenientes das diversas atividades do homem, que podem ser considerados como lixo.

A Agenda 21 refere quea problemática do lixo remete a uma ampla e necessária discussão sobre saúde coletiva, discussão essa que considera a estimativa de que, no âmbito mundial, aproximadamente 5,2 bilhões de indivíduos - incluindo 4 milhões de crianças - morrem anualmente em consequência de doenças relacionadas ao lix ${ }^{11}$.

\section{O tamanho do problema}

A questão do tratamento adequado para o lixo urbano évista com um baixo nível de prioridade pelas autoridades competentes e o que temos é tão somente esforços para recolhêlo e depositálo em locais distantes e escondidos dos olhos da parcela mais privilegiada da população. Com a elevação na geração de resíduos, sejam eles de origem doméstica, industrial ou de serviços de saúde, que apresentam periculosidade, gerando impactos específicos, os riscos à saúde pública passam a ser potencializados enecessitam decuidados especiais ${ }^{19}$.

Calderoni ${ }^{19}$ aponta que metade a dois terços do lixo sólido das residências, em cidades de renda mais baixa, não é coletado. Ao mesmo tempo, a administração dos resíduos urbanos consome de 20 a $40 \%$ dos orçamentos municipais em cidades mais pobres.

D'Almeida e Vilhena ${ }^{22}$ apontam que vários fatores importantes interferem na produção de resíduos da sociedade, primeiramente a densidade populacional de um município, o poder aquisitivo de seus moradores e seus hábitos de consumo.

0 contexto urbano das cidades tem se configurado em grandes desafios para quem pensa, sente ou age nesses espaços.

A teoria de $M$ anuel Castell $s^{12}$ refere ser a característica econômica que determina todo o processo de urbanização de um espaço. Na perspectiva do autor, a cidade, através de seus compartimentos espaciais específicos, seus diversos espaços, incrementa a reprodução da força de trabaIho, pois, na medida em que o consumo se torna uma questão coletiva, a questão urbana se transforma numa questão política.

0 termo urbanização, segundo Castells, tem dois sentidos distintos: um que determina que a concentração espacial de uma população acontece a partir de certos limites de dimensão e de densidade; e num segundo sentido, a urbanização emerge também em função da propagação de um sistema de valores, atitudes e comportamentos denominado como cultura urbana ${ }^{12}$.

Assim, a cidade passa a ser vista como uma unidade de produção complexa, com uma grande variedade de bens eserviços, o que exerceuma forte atração sobre os seres humanos. A urbanização tem sido apontada como indutora de amplas transformações no estilo de vida do homem, com aumento da deterioração de sua qualidade de vida.

0 resultado desse movimento é a exclusão social e a precariedade que caracteriza o espaço urbano dos territórios e a deterioração da qualidade de vida das populações ${ }^{23}$.

Paralelamente, argumenta que a urbanização através do modo de vida urbano instituído, particularmente as nossas estruturas de repartição do trabalho e de funções, ocupação dos solos, transportes, produção industrial, agricultura, consumo e atividades recreativas, nos responsabiliza pelos numerosos problemas ambientais com os quais a humanidade se confronta. Este fato é extremamenterelevante, principal mentese considerarmos que mais de $78 \%$ da população mundial vivem nas zonas urbanas ${ }^{19}$.

Para Calderoni ${ }^{19}$, as cidades que crescem em demasia acabam por exceder o chamado "tamanho ideal" e passam a impor problemas que se fazem refletir nos custos de produção, na saturação dos sistemas de abastecimento de água, no elevado tempo de viagem imposto aos trabal hadores, fruto das dificuldades no trânsito, nos problemas de abastecimento, nas restrições para 
resolver a questão dos rejeitos, no surgimento das chamadas economias informais e, consequentemente, nos trabalhadores informais, e assim por diante.

Por conseguinte, o processo de urbanização raramente éinduzido por uma política governamental ordenada, processando-se de modo descontrolado e forçando as cidades a abrigarem um número de pessoas superior à sua capacidade, o que dá origem a habitações "subnormais", aos "sem-teto", à violência, à poluição, entre outros agravantes ${ }^{24}$.

\section{Catadores de lixo: uma exclusão provocada}

Em atenção ao enfoque dessa investigação, é necessário evidenciar os efeitos provocados pelos padrões de produção e consumo da sociedade moderna. Com um ritmo sem precedentes, tanto a quantidade como a variedade de resíduos tem se modificado ao longo dos anos, causando impacto tanto no ambiente como na saúde de toda a população.

0 modelo de consumo adotado pela sociedade contemporânea acarreta o esgotamento dos recursos naturais, o agravamento da pobreza e do desequilíbrio, porque pautado na acumulação e no desperdício. Surge daí a expressão "descartável", que passou a ser utilizada sem muito controle, desencadeando dois processos: de um lado, a quantidade e a qualidade dos resíduos gerados e, por outro lado, frente às políticas econômicas e sociais, uma massa de excludentes, que passaram a se "beneficiar" dessa geração, que éa população de catadores de materiais recicláveis. Os indivíduos que vivem da coleta de materiais recicláveis, entendida como meio de sobrevivência e de obtenção de renda, ainda são pouco estudados pela saúde pública ou qualquer outra área ${ }^{25,26}$.

A temática apresenta relevância social a partir do elevado número de catadores de materiais recicláveis em todo país. Alguns estudos advertiram que, no final da década denoventa, existiam 45 mil crianças e adolescentes vivendo e trabaIhando em lixões ${ }^{25}$.

De acordo com cálculos da Associação do Compromisso Empresarial para Reciclagem (CEM PRE), até 1998 existiam mais de quinhentos mil catadores de lixo trabal hando oficialmente no Brasil. Grande parte dessas pessoas está organizada em pequenas cooperativas, que surgem com apoio de comunidades locai $5^{27}$.

Em 2006, o M ovimento Nacional de Catado- res de M ateriais Recicláveis aponta para um número de aproximadamente oitocentos mil catadores, organizados em cooperativas ou associações, demonstrando a legitimidade da atividade ${ }^{28}$.

Os estudos realizados apontam para um perfil de catadores, subdivididos em três categorias: catadores de rua, catadores cooperados e catadores delixão. Denomina-secatador de rua a categoria que coleta em sacos de lixo colocados pela população na rua, pelo comércio local ou pelas indústrias, tendo sua própria carroça ou qualquer outro transporte adaptado para carga. Os catadores cooperativados eautogestionários são aqueles que prestam serviço de coleta sel etiva de qualidade, de forma articulada e organizada, gerando trabalho erenda. Estesseorganizam nacionalmente no M ovimento $\mathrm{N}$ acional dos Catadores, têm apoio de diversas organizações não governamentais e estão articulados em fóruns, buscando consolidar a sua participação nos programas municipais de coleta seletiva. Os catadores de lixão encaixam-se na relação direta de exclusão social, são aqueles que fazem a catação diretamente nos lixões dos municípios equeestão desvinculados de qualquer assistência e organização 29,30.

Em face ao alto índice de desemprego, a estratégia de sobrevivência encontrada pela população de excluídos é "coletar lixo" como forma de obter a renda para o próprio sustento. Ao catar e separar os materiais recicláveis, seja em lixões, em ditos "aterros sanitários" ou ainda em usinas de reciclagem por todo país, o catador constitui atualmente um importante elo do sistema de reciclagem. Infelizmente, as iniciativas brasileiras de coleta seletiva ainda são poucas. 0 Estado de São Paulo apresenta uma maior porcentagem: cem dos 645 municípios desenvolvem algum tipo de programa desta natureza ${ }^{26,31}$.

Segundo Calderoni ${ }^{19}$, o mais comum é a criação de uma situação em que pessoas pobres convivem da pior maneira possível com resíduos que podem até fornecer um precário sustento, mas que certamente trarão doenças, agravarão as condições de vida da população e contribuirão para contaminar 0 ambiente. Como 0 lixo é considerado um achado valioso pela população carente, os catadores constituem-se em uma comunidade de risco, não apenas para sua própria integridade física e de saúde, como também são submetidos a uma condição de marginalidade social e econômica, que muitas vezes se confunde com o próprio conceito de lixo.

Poucos são os trabalhos que relacionam os riscos à saúde pública e seus efeitos na atividade de catação, mas acidentes com cortes, perfura- 
ções, queimaduras, dermatites são consequências desse contato, além de alta incidência de intoxicações alimentares e doenças parasitárias. Embora pouco relatadas nos trabalhos científicos publicados, suspeita-se que haja associação também com doenças infecto-contagiosas, como hepatite viral e aids ${ }^{25}$.

Segundo Sisinno ${ }^{32}$, os resíduos sólidos urbanos devem ser compreendidos como um problema de saúde pública e que as consequências de seu manejo e disposição final inadequado acabam se refletindo direta e indiretamente na saúde da população.

\section{Reciclagem: uma realidade?}

Contraditoriamente, o Brasil é hoje uma referência mundial em termos de reciclagem. Atualmente, o país é recordista na transformação de latas dealumínio e apresenta índices elevados de reciclagem deváriostipos de embalagem, principalmenteconsiderando o fato desteprocesso não ser obrigatório por lei, como acontece em outros grandes países recicladores ${ }^{31}$.

Conforme mostra a Pesquisa Ciclosoft 2002, realizada pelo Compromisso Empresarial para Reciclagem (CEM PRE), nos últimos oito anos, os programas de coleta seletiva tiveram um incremento de $138 \%{ }^{27}$.

Atualmente, 192 municípios operam essas iniciativas. 0 Estado de São Paulo apresenta o maior número de programas de coleta seletiva, 57 no total. Em seguida, vem o Rio Grande do Sul (42), Santa Catarina (22), M inas Gerais e Paraná (18) e o Rio de Janeiro (9). Apesar do crescimento apontado pela pesquisa, são tímidos os números apresentados pelo país nessa área. Temos 5.561 municípios; portanto, apenas $3,5 \%$ desse universo operam programas de coleta seletiva ${ }^{27}$.

É fundamental que o governo e a sociedade assumam novas atitudes, visando gerenciar de modo mais adequado a grande quantidade e diversi dade de resíduos que são produzidos diariamente nas empresas e residências ${ }^{30}$.

Pensar a educação ambiental requer uma reflexão sobre os pressupostos dos processos produtivos, das mudanças nos hábitos de consumo, na urbanização sem causar impacto, gerando formas alternativas de produção energética e distribuição de renda. Enfim, criar eestabelecer novos princípios e val ores que perpassam pela cooperação e transformação do atual modelo.

\section{Conclusões}

Os riscos à saúde pública, relacionados aos resíduos sólidos, decorrem da interação de uma variedade de fatores que incluem aspectos ambientais, ocupacionais e de consumo, entre outros.

É tarefa, tanto do Poder Público como da sociedade organizada, estimular debates que levem à revisão dehábitos de consumo. A sociedade mostra-se sensível ao problema quando reage positivamente ao apelo de participar de programas públicos de coleta seletiva delixo ou quando toma a iniciativa de promover a separação de materiais, no caso deescolas, universidades, condomínios residenciais.

Além de revisar seus valores e práticas, cabe ainda aos cidadãos o papel de pressionar governos eempresariado na definição de metas eestratégias para que, num horizonte mínimo, garanta-se um padrão de produção e consumo em que as condições de reprodução da vida na Terra estejam asseguradas, com oportunidades justas para todos, num ambiente equilibrado e saudável.

Ademais, o processo de reciclagem é uma medida paliativa. Os geradores, que somos todos nós, devem ter em mente que é imperativo reduzir o consumo supérfluo, evitando desperdícios, separar o material reciclável na fonte (residência, indústria, comércio), reaproveitando os produtos ao máximo para que a prática do consumo consciente seja uma alternativa viável.

É de vital importância a tomada de consciência de que os atuais níveis de consumo dos países industrializados não podem ser alcançados por todos os povos que vivem na Terra e, muito menos, pelas gerações futuras, sem destruição do capital natural. Portanto, o gerenciamento dos resíduos sólidos tem uma relação com o processo de conscientização da população quanto aos padrões de consumo, da importância da reutilização de diversos materiais e da prática da coleta sel etiva. Dessa forma, a educação ambiental deve estar presentee em consonância com as políticas públicas de redução e destinação do lixo.

\section{Colaboradores}

M M Siqueira e MS de M oraes participaram da concepção do estudo, coleta e análise dos dados, redação e revisão do artigo. 


\section{Referências}

1. Bottomore $\mathrm{T}, \mathrm{N}$ isbet R, organizadores. História da análise sociológica. Rio de Janeiro: Zahar; 1980.

2. Freitas CM. Problemas ambientais, saúde coletiva e ciências sociais. Cien Saude Colet 2003; 8(1):137-150.

3. Brasil. Ministério da Saúde. Política nacional de saúde ambiental para o setor saúde. [site da Internet]. 1999 [acessado 2006 fev 24]. Disponível em: http://portal.saude.gov.br/portal/svs

4. Augusto LGS, Câmara VM, Carneiro FF, Câncio J Gouveia N. Saúde e ambiente: uma reflexão da Associação Brasileira de Pós-Graduação em Saúde Coletiva (ABRASCO). Rev. bras. epidemiol. 2003; 6(2):87-94

5. Paim JS, Almeida F. Saúde coletiva: uma "nova saúde pública" ou campo aberto a novos paradigmas? Rev. Saude Publica 1998; 32(4):299-316.

6. M inayo MCS, Hartz ZM A, Buss PM. Qualidade de vida e saúde: um debate necessário. Cien Saude Colet 2000; 5(1):7-18

7. Leff E. Saber ambiental: sustentabilidade, racionalidade, complexidade, poder. 35a ed. Petrópolis: Vozes; 2001.

8. Carvalho ICM . O "ambiental" como valor substantivo: uma reflexão sobre a identidade da educação ambiental. In: Saúvé L, Orellana I, Sato $M$, organizadores. Textos escolhidos em educação ambiental de uma América a outra. Montreal: Publications EREUQUAM ; 2002. p. 85-90.

9. Giddens A. As consequências da modernidade. São Paulo: Unesp; 1990.

10. Novaes W. Os desafios do século XXI. Estud Av 2000; 14(40):107-115.

11. Brasil. Ministério do M eio Ambiente. Agenda 21 Conferência das Nações Unidas sobre M eio Ambiente e Desenvolvimento. [site da Internet]. [acessado 2006 fev 24]. Disponível em: http://www.ambiente. sp.gov.br/ppma/agenda.htm

12. Castells M. A questão urbana. Rio de Janeiro: Paz e Terra; 1983

13. Waldman M. Ecologia e lutas sociais no Brasil. São Paulo: Contexto; 1997.

14. Cavalcanti FCU, Cavalcanti PCU. Primeiro cidadão, depois consumidor. Rio de Janeiro: Civilização Brasileira; 1994

15. Pádua JA. Produção, consumo e sustentabilidade: 0 Brasil no contexto planetário [Cadernos de Debate do Projeto Brasil Sustentável e Democrático, 6]. Rio de Janeiro: FASE; 1999.

16. Novaes W. Em busca do caminho das pedras. [site da Internet] 2004 [acessado 2005 set 24]. Disponível em: http://www.comitepaz.org.br/W N ovaes.htm

17. Portilho M FF. Profissionais do lixo: um estudo sobre as representações sociais de engenheiros, garis e catadores [dissertação]. Rio de Janeiro (RJ): Instituto de Psicologia/Programa Eicos, Universidade Federal do Rio de Janeiro; 1997.
18. Santos BS. Pela mão de Alice: 0 social e o político na pós-modernidade. São Paulo: Cortez; 1999.

19. Calderoni S. Os bilhões perdidos no lixo. 3a ed. São Paulo: Humanitás Livraria/FFLCH/USP; 1999.

20. Capra F. 0 ponto de mutação. 23a ed. São Paulo: Cultrix; 2002

21. Miranda LL. 0 que é lixo. São Paulo: Brasiliense; 1995.

22. D 'Almeida M LO, Vilhena A. Lixo municipal: manual de gerenciamento integrado. $2{ }^{a}$ ed. São Paulo: IPT/CEM PRE; 2000.

23. Maricato $E$. Planejamento urbano no Brasil: as idéias fora do lugar e o lugar fora das idéias. In: Arantes $O B, M$ aricato $E$, Vainer $C$, organizadores. $A$ cidade do pensamento único: desmanchando consensos. Rio de Janeiro: Vozes; 2003. p.121-192.

24. Singer PA. Guisa de introdução: urbanização e classes sociais. In: Singer PA, organizador. Economia política da urbanização. São Paulo: Brasiliense; 1977. p.11-28.

25. Porto MFS, Juncá DCM, Gonçalves RS, Filhote MJF. Lixo, trabalho e saúde: um estudo de caso com catadores em um aterro metropolitano no Rio de Janeiro, Brasil. Cad Saude Publica 2004; 20(6):1503-1514.

26. Ferreira SL. Os catadores do lixo na construção de uma nova cultura: a de separar o lixo e da consciência ambiental. Rev U rutágua - Rev Acad Multidisc [periódico na Internet]. 2002 ago-nov [acessado 2006 mar 03]; 7:[cerca de 6 p.]. Disponível em: http://www.uem.br/urutagua/007/07ferreira.htm

27. Cempre - Compromisso empresarial para reciclagem. [site da Internet]. [acessado 2006 mai 28]. Disponível em: http//:www.cempre.org.br

28. Movimento $\mathrm{N}$ acional de Catadores de $\mathrm{M}$ ateriais Recicláveis. [site da Internet]. [acessado 2006 mar 03]. Disponível em: http://movimentonacional catadores.org.br

29. 29. Ferreira JA, Anjos LA. Aspectos de saúde coletiva e ocupacional associados à gestão dos resíduos sólidos municipais. Cad Saude Publica 2001; 17(3):689-696.

30. Grimberg E, Blauth P. Coleta seletiva: reciclando materiais, reciclando valores. São Paulo: Pólis; 1998

31. Rodrigues FL. Lixo: de onde vem? para onde vai? São Paulo: Moderna/USP; 1998.

32. Sisinno CLS, Oliveira RM, organizadores. Resíduos sólidos, ambiente e saúde. Rio de Janeiro: Fiocruz; 2002.

Artigo apresentado em 05/08/2007

Aprovado em 08/02/2008

Versão final apresentada em 05/05/2008 